\title{
Assessment of motivation, expectations and satisfaction of adult patients submitted to orthodontic treatment
}

\author{
Patrícia Gomide de Souza Andrade Oliveira¹, Rubens Rodrigues Tavares², Jairo Curado de Freitas ${ }^{3}$
}

Objective: The purpose of this study was to analyze the psychological aspects of adult patients who sought and underwent orthodontic treatment, evaluating their expectations and discomfort during treatment, as well as their satisfaction after completion of dental movement. Results and Conclusions: Data obtained from previous published papers, and also from questionnaires answered by 54 patients, showed that adult patients stood out for their attention to details and high interest in the esthetic improvements provided by treatment, and also for a greater perception of their initial malocclusion. On the other hand, the same data showed that adult patients, once informed about the limitations of their treatment and having confidence on the orthodontist, presented a high level of satisfaction with treatment results, revealing themselves as good patients for indication and execution of orthodontic procedures.

Keywords: Orthodontics. Psychology. Behavior. Adults.

Objetivo: o propósito desse trabalho foi analisar as características psicológicas dos pacientes adultos que procuraram e se submeteram a tratamentos ortodônticos, avaliando suas expectativas, desconforto durante o tratamento e satisfação final após a conclusão das movimentações dentárias propostas. Resultados e Conclusões: os dados obtidos por meio de uma revisão bibliográfica e de questionários realizados com 54 pacientes demonstraram que os pacientes adultos se destacaram por serem mais detalhistas e exigentes em relação às melhoras estéticas proporcionadas pelo tratamento, e por apresentarem uma maior percepção de sua má oclusão antes do início do tratamento. Por outro lado, esses mesmos dados demonstraram que os pacientes adultos, uma vez bem esclarecidos sobre as limitações peculiares ao seu tratamento e sentindo-se bem amparados e orientados pelos profissionais responsáveis, apresentaram um alto índice de satisfação frente aos resultados finais do tratamento, sendo ótimos pacientes para a indicação e execução de procedimentos ortodônticos.

Palavras-chave: Ortodontia. Psicologia. Comportamento. Adulto.

${ }^{1}$ Specialist in Orthodontics.

${ }^{2}$ Professor of the Orthodontics Specialization Program at the Brazilian Dental Association - Goiás Section (ABO-GO).

${ }^{3}$ Head of the Orthodontics Specialization Program, ABO-GO.
How to cite this article: Oliveira PGSA, Tavares RR, Freitas JC. Assessment of motivation, expectations and satisfaction of adult patients submitted to orthodontic treatment. Dental Press J Orthod. 2013 Mar-Apr;18(2):81-7.

Submitted: June 22, 2009 - Revised and accepted: October 26, 2010

» The author reports no commercial, proprietary or financial interest in the products or companies described in this article.

Contact address: Patrícia Gomide de Souza Andrade Oliveira Rua 1028 n. 131, ap. 503, setor Pedro Ludovico CEP: 74.823-130 - Goiânia / GO, Brazil E-mail: drapatriciagomide@yahoo.com.br 


\section{INTRODUCTION}

Many authors confirm what orthodontists have been noticing on a daily basis in their private practices: The increasing number of adult patients seeking orthodontic treatment. ${ }^{3,4,6}$

When planning orthodontic treatment for patients in that scope, we should bear in mind that, generally, adults present a different experience in relation to buccal pathologies, and psychological limitations when compared to teenagers and children.

Focusing in the psychological aspects concerning adult patients, many studies prove that these patients have a greater awareness of their malocclusion, which may generate very optimistic expectations about the final results of their treatment. ${ }^{4,10,11}$ In search for delivering a more efficient treatment to such patients, it is mandatory that orthodontists investigate and understand the expectations, difficulties, and motivations of this increasing group, in order to offer assistance that matches their concerns.

The offer of orthodontic treatment to adult patients, albeit becoming more common in the last decades, is not a product of our time. The first reference to it was made by Pierre Fauchard, author of the first scientific Dentistry book known to us as Le Chirurgien Dentiste from $1723 .{ }^{6}$

Epidemiologic data that has been gathered since the 80 's confirms the increase of the demand of patients in that age group $(18+)$ who want and need orthodontic treatment. In the United States, in 1988, it became clear that in large urban business centers, this demand represented between 60 to $70 \%$ of all the patients looking for treatment. In Europe, studies from the beginning of the 80 's also show an increase in adult patients seeking orthodontic care. ${ }^{6,11}$

Recent studies show that the frequency of malocclusion in adults is similar, if not higher to that observed in children and teenagers. According to official data released by the North American government in the NHANES III (Third National Health and Nutrition Survey), in the 90 's, only $41.1 \%$ of all American adults had an optimal overjet, 49\% presented deep bite, 3.3\% open bite, and there was also a significant occurrence of misalignment in upper and lower incisors, respectively $56 \%$ and $62.9 \% .^{3,12}$ In a similar way, the prevalence of malocclusion in Eastern Europe adults, according to studies conducted within populations from Germany and Sweden, reached between 40 and $76 \%$ of the total adult population from these regions. ${ }^{3}$
In 2003, a study made with 200 adult patients, evaluated the reasons which led them to initially reject the suggestion to undergo orthodontic treatment. The researchers found out the reasons to be, from the highest to the lowest prevalence: Long treatment time, the discomfort of wearing orthodontic appliances, rejection to the anti-esthetic appearance of brackets, concerns about pain, and fear of disappointment with the final treatment result. ${ }^{7}$

Within the large demand of adult patients who seek and need orthodontic assistance, literature has shown that most of these patients are females, ${ }^{6,10}$ and that the indication for them to seek for an orthodontist comes from the family dentist. ${ }^{6}$

Just like every health related treatment, orthodontic treatment in adults has its indications and contraindications, which must be carefully assessed before any action takes place.

Highlighted among the indications are: The possibility of improving teeth implantation in the periodontal tissues, determining a more stable and harmonious occlusive pattern, distribution of edentulous spaces so that they can be restored later, improvement of the occlusal condition and protection of the stomatognathic system (especially the temporomandibular joint - TMJ) and satisfaction of the patients esthetical demands.

The cases where orthodontic treatment would be contraindicated in adult patients are: Existence of severe skeletal discrepancies (in these cases surgical treatment would be preferable), patients with systemic or advanced local diseases, cases of severe alveolar bone loss, when the results might not fulfill the expectations of both the patient and the professional in charge of the treatment, questionable prognostic stability, and lack of patient interest or motivation. ${ }^{13}$

The main reason that leads adult individuals to search for orthodontic care is their dissatisfaction with their dental and/or facial appearance; and many studies confirm that adult patients have greater perception of their dental esthetics thus presenting higher demands concerning the results achieved after orthodontic therapy., ${ }^{4,5,9}$ Another frequent reason is the need for isolated dental movements so that other procedures aiming the control of periodontal disease prosthetic rehabilitation (implants or prosthesis), or cosmetic (dental reconstructions) can be executed within a multidisciplinary planning. ${ }^{6}$

Previous studies that proposed to evaluate the psychological profile of adult patients seeking orthodontic 
treatment showed that many of these patients presented a neurotic or unstable psychological profile along with problems of self-esteem. These same studies alert orthodontists that this kind of patient tends to nurture great expectations, some of them even being unreal, regarding treatment results, and suggesting that the tangible results should be made as clear as possible to them in order to avoid future disappointments. ${ }^{4,10,11}$

In 2005, researchers gave a satisfaction questionnaire to be answered by 100 patients treated in the Academic Center of Dentistry in Amsterdam three years after they completed their orthodontic treatment. In that study it was observed that the most important issue in determining patient satisfaction was the good orthodontist/ patient relationship during treatment and that female patients revealed lower satisfaction levels with the dentofacial improvements achieved by treatment when compared to male patients.

The objective of the present study was to analyze, through questionnaires the psychological profile of adult patients, most of them living in the city of Goiânia/GO, Brazil, who underwent orthodontic treatment, assessing their expectations, discomfort during treatment, and final satisfaction after completion of the dental movements, in order to serve as a guideline for orthodontists during planning and executing their clinical treatment focusing on the satisfaction of their patients, minimizing their discomfort, and establishing special procedure protocols for such patients.

\section{MATERIAL AND METHODS}

The material used in the present study was a set of 54 questionnaires given to adult patients, most of them residents in the city of Goiânia/GO (Brazil), who had

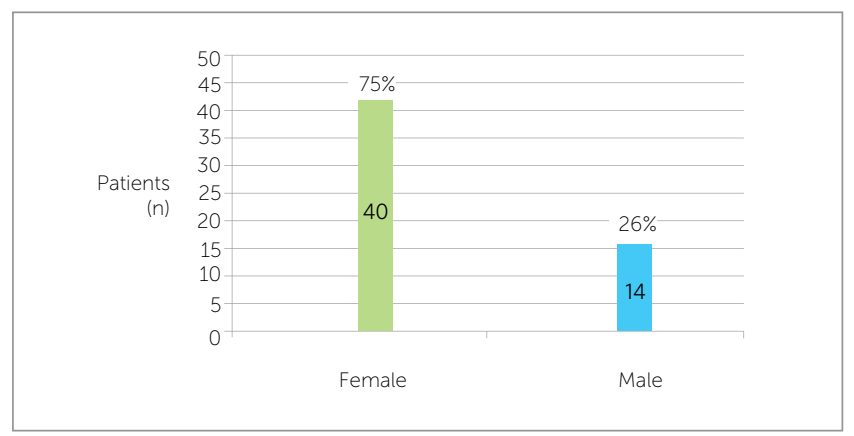

Figure 1 - Distribution of the sample by gender. received orthodontic treatment from dentists specialized in orthodontics living in that same city. Among the selected patients, 12 had completed their treatment at the Orthodontics Specialization Program Clinic at the $\mathrm{ABO}-\mathrm{GO}$ and 42 had been treated in private practices of orthodontists registered in the Regional Dental Council (CRO) as specialists.

The patients were selected according to the following inclusion criteria: 1 - completion of orthodontic treatment; 2 - Submitted to only one corrective orthodontic treatment; 3 - Treatment initiated after reaching the age of 20 years; 4 - Orthodontic treatment did not involve orthognathic surgical procedures; $5-\mathrm{Ab}-$ sence of any health problem that could influence in the orthodontic treatment.

Once selected, the patients were contacted by phone and were motivated to come either to the Orthodontics Specialization Program Clinic at the ABO-GO (patients who had been treated at that institution) or to the private practice of their respective orthodontists.

Concerning gender, 40 female patients and 14 male patients were evaluated (Fig 1).

The age which the patients started treatment ranged from 20 up to 61 years old, being that 29 of them started treatment in their second decade of life, 12 in their third decade of life, 07 in their fourth, and 06 after being 50 years old (Fig 2).

At the moment each patient arrived to the practice, they were given the Informed Consent and after signing it, they all answered a questionnaire with 9 objective questions concerning the topic that was being investigating. The questions were tailored so that they could answer them fast and objectively, and some blank space was given so that they could include personal considerations.

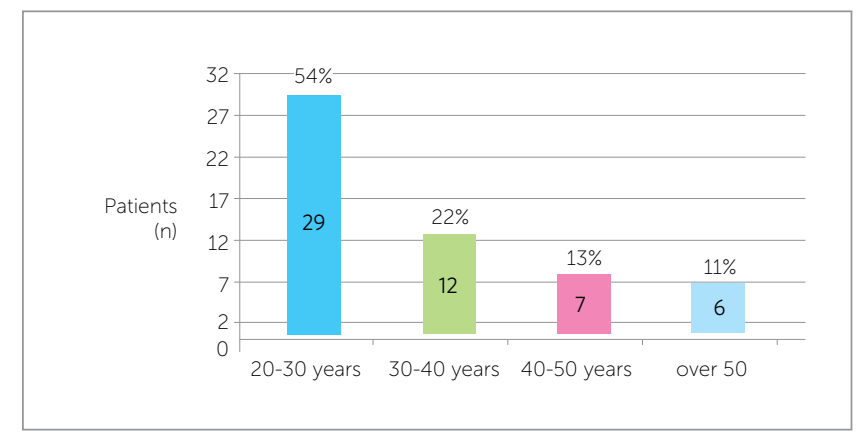

Figure 2 - Distribution of the sample according to the age at the beginning of the performed orthodontic treatment. 
The data contained in the questionnaires were classified and transformed into tables and descriptive statistics were made.

\section{RESULTS}

Assessment of the answers to the questionnaire.

When the patients were asked about the reason for them to seek treatment only when adults, the answers were: 31\% for a previous lack of financial means; 30\% were not previously bothered with the position of their teeth; 14\% looked for treatment after being told (insistently) by their general dentists; $9 \%$ said they didn't know orthodontics could solve their dental problems; $2 \%$ believed orthodontic treatment was only suitable for teenagers and children, and 14\% mentioned other reasons, and among these we found: The wish and the need of a better facial look, the need of preparation for dental implants, speech therapist recommendation, and TMJ discomfort (Fig 3).

Trying to assess the perception of malocclusion, before the beginning of orthodontic treatment, the patients informed that the aspects that were most annoying them were: The poor appearance of the smile, 36 patients (61\%); 09 patients pointed to problems with chewing (15.2\%); 08 patients pointed to the empty spaces due to tooth loss (13.5\%); 04 pointed to periodontal problems (inflammation, tooth mobility) corresponding to $6.7 \%$ of the answers; and 02 pointed to difficulty in speaking (3.3\%), being that 05 out of the 54 patients marked 2 answers to this question (Table 1 ).

When answering about the reasons for rejecting the initial indication to undergo orthodontic care, the answers were: $55.3 \%$ felt concerned with the perspective of the long duration of treatment; 17.8\% had doubts about the true efficiency of orthodontic intervention; $12.5 \%$ were afraid of feeling pain during treatment; $10.7 \%$ rejected the unpleasant appearance of braces; and $3.5 \%$ said they had never rejected the idea of undergoing an orthodontic treatment (Table 2).

In relation to the reasons which led the patients to make the choice for receiving orthodontic treatment it was found that: $35.5 \%$ said about the suggestion of a general dentist; $27.1 \%$ already wanted to undergo treatment; $22 \%$ made up their minds after talking to an orthodontist; $11.8 \%$ told they were influenced by the opinion of their relatives and friends; and 3.3\% mentioned different reasons, such as the opportunity to

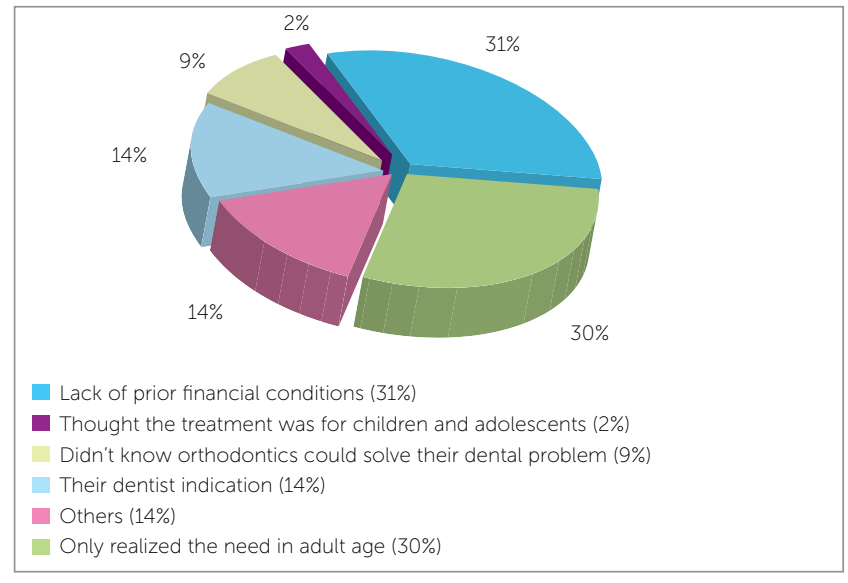

Figure 3 - Reasons that led patients to seek orthodontic treatment only in adult age.

avoid a possible orthognathic surgery and the wish to receive dental implants afterwards. The data referring to the previous question are available on Table 3 , and each patient could check more than one answer.

Regarding the discomforts experienced throughout treatment, 22 patients complained of pain after activation appointments (40\%); 13 complained about the long time of active treatment (23.6\%); 09 patients $(16.3 \%$ from the total) claimed they hadn't felt any discomfort during orthodontic treatment; 06 pointed to difficulties in dental hygiene and flossing, associated with wounds on their inner cheeks, as the main reason for discomfort (10.9\%); 03 people were concerned about the unpleasant look of their braces (5.4\%); 01 patient complained about periodontal inflammations linked to the treatment (1.8\%); 1 complaint about recurrent aphthous lesions during treatment, and none felt embarrassed about being among much younger patients at the orthodontic practice environment (Table 4).

The most important positive change observed by patients after treatment conclusion was: The improvement of facial appearance for 39 patients (72.2\%); 13 noticed changes in their chewing and/or speaking pattern (24\%); 07 reported improvements in their periodontal conditions along with a better implantation of their teeth (12.9\%); 01 patient checked all the answers above and 08 checked two answers (Table 5).

When comparing the actual results obtained with the pre-treatment expectations: 50\% considered the obtained results to be better than what they had expected; for $46.2 \%$ the results were similar to what they had expected; $3.7 \%$ considered that their expectations 
Table 1 - Patients perception of their smile, prior to orthodontic treatment.

\begin{tabular}{lc}
\hline $\begin{array}{l}\text { Before the treatment, what was your chief complaint about your } \\
\text { teeth? }\end{array}$ & 36 \\
\hline Bad esthetics & 09 \\
Mastication problems & 08 \\
\hline Edentulous space (closed during treatment) & 04 \\
Gingival problems (inflammations, tooth mobility) & 02 \\
Speaking problems & 05 \\
\hline Number of patients that checked two answers &
\end{tabular}

Table 2 - Reasons most mentioned for initial rejection of the treatment suggested

What was bothering the most in the orthodontic treatment idea?

Long duration

31

Doubts on the treatment efficiency

Fear of feeling pain

Unaesthetic aspect of the appliance

Nothing

Number of patients that checked two answers

Table 3 - Determining factor in deciding for starting the treatment.

What made you start the orthodontic treatment?

Dentist orientation

21

You wanted already to receive the treatment

16

Chat with the orthodontist

13

Opinion and support from family, spouse and friends

07

Others (avoid orthognathic surgery, implants need)

Table 4 - Main discomfort brought by the treatment.

\begin{tabular}{ll}
\hline During treatment, what most displeased you? & \\
\hline Pain during and after activation sessions & 22 \\
\hline Found the treatment too long & 13 \\
\hline Nothing & 09 \\
\hline Difficulty in cleaning and wounds in the mucosa. & 07 \\
\hline Felt embarrassed with the appearance with appliance & 03 \\
Gingiva inflammation & 01 \\
\hline Recurrent ulcer & 01 \\
\hline Embarrassment in contact with children and adolescents & 00 \\
\hline
\end{tabular}

Table 5 - Subjective perception of patients front orthodontic treatment results.

\begin{tabular}{lc}
\hline After treatment, which motivation did you noticed more? & \\
More beautiful smile (facial esthetic improvement) & 39 \\
Speech and mastication pattern improvement & 13 \\
Gingival and tooth implantation condition improvement & 07 \\
Others & 04 \\
\hline Note: A patient marked all the answers and eight others marked two answers.
\end{tabular}

before treatment were fairly achieved; and none of them considered the treatment results to be inferior to their initial expectations.

In a question aiming to know if they would undergo orthodontic treatment again, it was concluded that $100 \%$ of patients did not regret undergoing it, and all of them said they would, based on their personal experience, encourage other adults to go through orthodontic treatment if necessary

\section{DISCUSSION}

This study consisted in the subjective evaluation of 54 adult patients in the fixed retention stage. The predominance of female patients (74\%) is consistent with data found in previous studies that suggested that women have a greater motivation to undergo orthodontic treatment when compared to men.

As seen in the results, when questioned about the reasons that led them to look for orthodontic assistance for the first time when in a more advanced age, the most common answers were the following in order of importance: $31.5 \%$ showed a previous lack of financial means; $29.8 \%$ reported that the awareness of the need for orthodontic treatment only raised at adult age. The high relevance of treatment costs seen in this local sample shows that this specific population has serious financial constraints, which sometimes may prevent them from gaining access to better health and well-being conditions.

When assessing the chief concern of adult patients who sought late orthodontic treatment, it is clear that most of the patients had esthetic reasons (61\%). This data corroborates with previous studies that show that the great majority of patients seek treatment to improve their smile esthetics and their facial esthetics. ${ }^{2,8}$

A previous study also evaluated the reasons that led some adult patients to initially reject the indication for orthodontic treatment and found the following reasons, in relevance order: Long duration of the proposed treatment; discomfort caused by the braces, rejection to the anti-esthetic look of brackets, fear of pain, and the fear of disappointment with the final results. ${ }^{7}$ When comparing the results achieved in this research with those of the one mentioned above, it is possible to observe in general, that patients showed similar doubts and concerns.

Among the factors indicated as determinant for the beginning of treatment were: A previous will to undergo it (27.1\% of the patients), which shows a good acceptance of 
adults when confronted with the indication for orthodontic treatment; $22 \%$ decided only after consulting with an orthodontist, which also highlights the importance of a good professional/patient relationship, and $11.8 \%$ made the decision influenced by spouses, friends and relatives.

In relation to the main discomforts experienced throughout the active treatment, the majority of patients complained about pain during treatment and immediately after the activation sessions (40\%); some complained about the long period of treatment (23.6\%); and $16.3 \%$ said they did not feel any discomfort or constraint. In previous studies, patients highlighted discomfort as the worst aspect of orthodontic treatment, although classifying this discomfort as mild and short lasting (with a duration average of 2 days after clinical activation of the appliances). In these same studies, orientation on the controlled use of painkillers and restriction in the ingestion of hard foods on the days following the activations were enough to significantly minimize the aforementioned discomfort. ${ }^{2,3}$

In a research made in 1981, all adult patients assessed, who were undergoing orthodontic care, considered the treatment advantageous despite the discomfort related to treatment; they did not regret having started it, and would suggest it to others who were in doubt about the cost-benefit ratio of orthodontic treatment. ${ }^{13}$ Other authors also found high level of satisfaction in patients when faced with the results achieved through the orthodontic treatment performed. ${ }^{3}$ These informations were also confirmed by the present study.

When evaluating the level of satisfaction of patients after treatment, it should be kept in mind that the analysis made by patients are based on subjective aspects and not technical ones, thus being under influence of different agents, such as, the kind of professional/patient relationship and variables such as gender. Another research in 2005 concluded that the most important aspect to affect the level of satisfaction of patients is not the final quality of the treatment done, but a good relationship between the patient and his orthodontist. According to that same research, women were more critical regarding treatment results, although in previous studies mentioned by these authors, men had shown to be more demanding and critical about the results of orthodontic treatment.

\section{CONCLUSION}

When assessing the characteristics of adult individuals that underwent orthodontic treatment, it was found that this group is mainly constituted by women, between 20 and 30 years old (53\%) who were not satisfied, mainly, with their smile esthetics (61\%).

When patients were asked about the reason for not seeking orthodontic treatment earlier, the great majority answered that they did not have financial conditions, or did not feel inconvenienced by the malocclusion they had. Unfortunately, the lack of economical conditions proved, at least in this set of Brazilian patients, to be a major restraint for them, having prevented their previous access to the facial and smile esthetics improvements they were longing for.

Individual clinical planning and clarity in procedures, previously discussed with patients, can minimize the main reasons for initial rejection from patients when faced with orthodontic treatment, which were: Aversion to the long duration of treatment $(55.3 \%)$, doubts about the efficiency of treatment (17.8\%), fear of pain (12.5\%), and discomfort with the esthetical aspect of fixed braces (10.7\%). A good relationship between the orthodontist, the general practitioner and other professionals involved with the patient, along with a clear and careful initial appointment can be considered decisive in making adult patients fell safe to effectively start orthodontic treatment.

Once the treatment is initiated, the information gathered suggests that orthodontists should be aware about reducing the discomfort felt during and after appliance activation appointments, which was a reason of complaint in $40 \%$ of the people interviewed; also to instruct their patients on dental hygiene techniques, and to elaborate a simplified treatment plan to reduce, according to the possibilities, the total treatment time (regarded as uncomfortably long for $23.6 \%$ of patients).

At last, when assessing patients already in retention, a high level of satisfaction was found for patients interviewed with regard to the final treatment results. This only shows that once patients are aware and clarified about the peculiar limitations of each clinical case, and when a trusting relationship between the patient and their orthodontist is established, adults are excellent candidates for orthodontic treatment. 


\section{REFERENCES}

1. Bos A, Vosselman N, Hoogstraten J, Prahl-Andersen B. Patient compliance: a determinant of patient satisfaction? Angle Orthod. 2005;75(4):526-31.

2. Breece GL, Nieberg LG. Motivation for adult orthodontic treatment. J Clin Orthod. 1986:20(3):166-71.

3. Buttke TM, Proffit WR. Referring adult patients for orthodontic treatment. J Am Dent Assoc. 1999 Jan;130(1):73-9.

4. Capelloza Filho L, Braga SA, Cavassan AO, Ozawa TO. Tratamento ortodôntico em adultos: uma abordagem direcionada. Rev Dental Press Ortod Ortop Facial. 2001;6(5):63-80.

5. Carvalho KV, Miguel JAM, Carlini MG. Satisfação dos pacientes submetidos a tratamento ortocirúrgico. Ortod Gaúch. 2001:5(1):49-56.

6. Khan RS, Horrocks EN. A study of adult orthodontic patients and their treatment. Br J Orthod. 1990;18(3):183-94.

7. Langlade M. Terapêutica ortodôntica. 3ạ. ed. São Paulo: Ed. Santos; 2003. $844 p$

8. McKiernan EX, McKiernan F, Jones ML. Psychological profiles and motives of adults seeking orthodontic treatment. Int J Adult Orthodon Orthognath Surg. 1992:7(3):187-98
9. Moyers RE. Ortodontia. 4a ed. Rio de Janeiro: Guanabara Koogan: 1999 $482 \mathrm{p}$

10. Nattrass C, Sandy JR. Adult orthodontics: a review. Br J Orthod 1995:22(4):331-7.

11. Proffit WR, Fields WH. Ortodontia contemporânea. 2 a ed. Rio de Janeiro Guanabara Koogan; 1995.

12. Proffit WR, Fields HW Jr, Moray LJ. Prevalence of malocclusion and orthodontic treatment need in the United States. Estimates from the NHANES III survey. Int J Adult Orthodon Orthognath Surg. 1998:13(2):97-106.

13. Tayer BH, Burek MJ. A survey of adult's attitudes toward orthodontic therapy. Am J Orthod. 1981;79(3):305-15.

14. Varela M, García-Camba JE. Impact of orthodontics on the psychologic profile of adult patients: a prospective study. Am J Orthod Dentofacial Orthop. 1995:108(2):142-8. 